\title{
Attitudes Toward Multiculturalism and Assimilation and Contact with Members of Outgroup
}

\author{
Sheruze Osmani Ballazhi
}

Safet Ballazhi

University of Tetova, Centar for Human Rights and Conflict Resolution

\begin{abstract}
Multicultural societies face the challenge of advancing intergroup relations. The group status in the society determines the presence of attitudes as well as mutual intergroup relations. The outgroup contact is one of the opportunities that assists the advancement of relations in the society. The goal of this study is to examine the differences of attitudes toward multiculturalism and assimilation in the majority and minority groups, and to which level we can predict the attitudes toward multiculturalism and assimilation based on the ethnic identity and contact with outgroup members. In this esearch, 361 youngsters are included. They are eighth and ninth grade students from five elementary schools in the city of Tetova, R. Macedonia. Of them, 166 study in Macedonian language, 195 in Albanian. To see the difference between the majority and minority group regarding the multicultural and assimilation attitude, t-test was used; for the prediction of intergroup attitudes, we used regressive analysis. The findings show that the minority group favors more multiculturalism while the majority group favors assimilation. As strong predictors of intergroup attitude, except ethnic identity, ethnic identification and outgroup contact appear as well. In order to advance the intergroup attitudes and relations as well as develop a multicultural society, the presence of outgroup members contact is important.
\end{abstract}

Keywords: multiculturalism, assimilation, ethnic identity, outgroup contact

\section{Introduction}

Countries with ethnic and cultural diversity are often challenged by intergroup relations. Psychologists provide models of intergroup relations which help societies with ethnic and cultural diversity fulfill the needs and interests of different groups. All of this serves for the purpose of advancing the relations and wellbeing of all society members. Berry (2011) offers the model that includes acculturation strategies and is based on the level of original culture maintenance and readiness to participate in contact with outgroup. According to him, when minority group members refuse to maintain their cultural identity and have a tendency to contact on daily basis with members of the other culture, it is known as the strategy of assimilation. When individuals show interest in maintaining their cultural identity but simultaneously conduct daily interactions with outgroup, it is known as integration. When integration is a feature of the society and it includes all ethnic groups then it is about multiculturalism.

Verkuyten (2004), defines multiculturalism as a provider of opportunity for equal participation of all groups in the society. Equality and discrimination prevention, stimulation of tolerance and respect toward outgroup are the basic tenets describing multiculturalism in Netherland (Verkuyten, 2004). Since ethnic groups with different social status have different goals, it is expected that preferences towards multiculturalism and assimilation will also be different, depending on the group status. Research studies confirm exactly the same. Minority group members express stronger support to multiculturalism than majority group members (Verkuyten, 2005; Verkuyten \& Martinovic, 2006), whereas majority group members favor assimilation or adapting to the dominant culture (Verkuyten \& Martinovic, 2006; Ajduković \& Corkalo, 2008). Furthermore, in-goup identification moderates multiculturalism impact. The more minorities support multiculturalism, the more they express their identification to ingroup. As for the majority group members, the more they express support to multiculturalism, the less they express identification to ingroup and express more positive attitude towards outgroup (Verkuyten, 2005). Majority group members express less positive attitude towards outgroup than members of minority groups and also express a lower level of ethnic identification (Verkuyten, 2005; Ajduković \& Čorkalo, 2008). 
Intergroup Contact Theory (Alport,1954) offers strategies to facilitate and reduce intergroup tensions and attitudes. According to this theory, the possibility of contact with members of different groups could stimulate more positive intergroup attitudes, respectively reduce prejudice and increase tolerance (Schlueter \& Scheepers, 2009; Brown et al., 2007; Verkuyten, 2009). The research conducted with pedagogical students in Macedonia who (in mixed groups) have participated in training on multiculturalism, respectively, who have participated three or more times in such training, express more positive attitudes toward the outgroup than students who have not taken part or have participated less than three times (Osmani Ballazhi et al, 2014). Research shows that the number of friends from outgroup is positively related to attitudes towards multiculturalism (Verkuyten \& Martinovic, 2006), and the more frequent the contact with outgroup members is, the more positive the attitudes towards the outgroup (Osmani Ballazhi et al., 2016). Čorkalo \& Ajduković (2008) argue that individuals who have more outgroup contact show greater tolerance towards outgroups and more positive attitudes towards cultural diversity, endorsement of multiculturalism. As for majority group members, the more they express they have outgroup member contact, the more they support multiculturalism (Verkuyten \& Martinovic, 2006). Intergroup contact reduces prejudice, nonetheless, it is even more effective when the contact contains a close relationship, a high quality intergroup relationship, as is friendship (Pettigrew \& Tropp, 2011). The findings of other research are in line with the abovementioned and indicate that individuals who have close contact including home visits to outgroup members express more positive intergroup attitudes than the ones who do not make such visits with outgroup members (Osmani Ballazhi et al., 2016). The more structural discrimination is perceived the more the support to multiculturalism is expressed in both, minority and majority groups. This is an indicator that multiculturalism is not only support to cultural diversity but it represents support to equal opportunities (Verkuyten \& Martinovic, 2006).

The goal of this study is to analyze the differences of attitudes toward multiculturalism and assimilation in majority groups (Macedonians) and minority (Albanians) as well as to which extent the intergroup attitudes can be predicted, based on ethnic identity and outgroup contact.

\section{Method}

\subsection{Sample and procedure}

There are 361 pupils of eighth and ninth grade included in the research. They all follow lessons in one language in the city of Tetova, either Macedonian or Albanian. From the total number of the included subjects in the research, 166 learn in Macedonian and 195 in Albanian language. The research is conducted from February to April 2017. The subjects filled out the questionnaire in their native language, during lessons in classrooms. The duration of filling out the questionnaire was 40 minutes.

\subsection{Measuring instruments}

The tolerance towards ethnic diversity/attitude towards multiculturalism scale is used to measure attitudes towards multiculturalism (Čorkalo Biruški \& Ajduković, 2008). The scale consists of nine items and has shown good reliability in previous measurements ( $\alpha=0.66-0.79$, Biruški Čorkalo \& Ajduković, 2012). It has shown a good reliability in this research as well $(\alpha=0.80)$. The subjects were asked to express on how much they agree to each item in a scale from 1 (totally disagree) to 4 (completely agree). The highest result achieved in the scale indicates higher tolerance of the subjects towards multiculturalism. Example item: „Ethnic minorities enrich the culture of every nation“. The attitudes towards assimilation are measured by three items (Čorkalo Biruški \& Ajduković, 2008). The subjects had four options, starting from 1 (totally disagree) to 4 (completely agree) for each item. Example item: "The majority should determine the outline of education in a country. The scale reliability is satisfactory $(\alpha=0.73)$. National identity is measured by national identity scale (NAIT) (Čorkalo \& Kamenov, 2003), by 27 items. The subjects expressed on how much they agree to each item, starting from 1 (totally disagree) to 5 (completely agree). An item example is: „I consider that I am aware of my national identification“. The direct contact to outgroup members is measured through the item: „My personal contact with Albanians/Macedonians: I know they live in my city but I have no contact with them; I only have intermittent contact; I have acquaintances (I know them or greet on the street but we don't socialize); I have Macedonian/Albanian friends". The subjects were asked to choose one of the given answers, 1 (lack of contact) to 4 (friendly contact). The frequency of outgroup contact is measured through the item: "How often do they contact with outgroup members in the following ways: greeting, texting, participating in joint physical activities, spend free time together and home visits to outgroup members". The subjects answered on how often they contact through the five offered options, starting from 1 (never) to 5 (every day). 


\subsection{Research findings}

T-test is used to examine if there is difference in the attitudes toward multiculturalism between Albanian and Macedonian young people. The findings indicate that there is statistically significant difference in attitude toward multiculturalism between the two groups i.e. Albanian $(M=29.59, S D=4.36)$ and Macedonian $(M=27.27, S D=5.07), t(340)=7.4, p<0.01$. Specifically, unlike young Macedonians, Albanian youth expresses that they have a more favorable attitude towards multiculturalism. A statistically significant difference between young Albanians $(M=5.38, S D=1.96)$ and Macedonians ( $M$ $=8.89, \mathrm{SD}=2.15), \mathrm{t}(345)=3.6, \mathrm{p}<0.01$ have the attitudes towards assimilation. Young Macedonians express they favor more assimilation than the Albanian youth. Regarding the outgroup member contact, the data indicate that there is no statistically significant difference between Albanian $(M=2.55, S D=1.06)$ and Macedonian youth $(M=2.71, S D=0.95)$, $t$ (353) $6.8, p>0.05$.(Table 1.). There are no differences on all variables, multiculturalism, assimilation or contact, either by age groups. The eighth and ninth grade students who learn in Albanian as well as the ones learning in Macedonian language do not differ when favoring multiculturalism, assimilation or outgroup member contact is concerned. Furthermore, regarding the gender, girls and boys who learn in Macedonian language do not differ in favoring multiculturalism, assimilation or outgroup member contact. Regarding young people, respectively, young girls and boys who learn in Albanian, the only difference lies in favoring multiculturalism, namely, girls $(M=30.27, S D=4.70)$ comparing to boys who learn in Albanian $(M=28.98, S D=3.99) \mathrm{t}(187)=.01, p<0.05$, expressing they favor more multiculturalism. There are no differences in favoring assimilation and outgroup contact between girls and boys who learn in Albanian (table 2).

There are no differences between Albanian and Macedonian young people related to the frequency of texting, spending time together and home visits to each other. However, regarding the frequency of outgroup member contact, there is a weak but statistically significant difference related to the frequency of greeting each other as well as participating in joint physical activities, between the Albanian and Macedonian youngsters. Unlike Albanian young people $(M=3.15, S D=1.27)$, Macedonians $(M=3.54, S D=1.22), t(215)=.88, p<0.05$, declare that they greet Albanian youngsters more often. In addition, young Macedonians $(M=2.72, S D=1.24)$, compared to young Albanians $(M=2.33, S D=1.26), t(214)=20, p<0.05$ declare they participate more often in joint physical activities (table 3).

Table 1. Results of t-test and descriptive statistics for attitudes toward outgroup and contact with outgroup by ethnicity

ethnicity

\begin{tabular}{|c|c|c|c|c|c|c|}
\hline & \multicolumn{2}{|c|}{ Macedonian } & \multicolumn{2}{|c|}{ Albanian } & & \\
\hline & $\mathrm{M}$ & SD & $\mathrm{M}$ & SD & $\mathrm{t}$ & $\mathrm{df}$ \\
\hline Attitude toward multiculturalism & 27.27 & 5.07 & 29.59 & 4.36 & $7.4^{* *}$ & 340 \\
\hline Attitude toward assimilation & 8.89 & 2.15 & 5.38 & 1.96 & $3.6^{\star \star}$ & 345 \\
\hline Contact with outgroup & 2.71 & 0.95 & 2.55 & 1.06 & $6.8^{*}$ & 353 \\
\hline
\end{tabular}

Table 2. Results of t-test and descriptive statistics for attitudes toward outgroup and contact with outgroup by ethnicity and sex

ethnicity

\begin{tabular}{|c|c|c|c|c|c|c|c|c|c|c|c|c|}
\hline & \multicolumn{6}{|c|}{ Macedonian } & \multicolumn{4}{|c|}{ Albanian } & \multirow[b]{3}{*}{$t$} & \multirow[b]{3}{*}{ df } \\
\hline & \multicolumn{2}{|l|}{ male } & \multicolumn{4}{|l|}{ female } & \multicolumn{2}{|l|}{ male } & \multicolumn{2}{|c|}{ female } & & \\
\hline & M & SD & M & SD & $t$ & df & M & SD & M & SD & & \\
\hline $\begin{array}{l}\text { Attitude toward } \\
\text { multiculturalism }\end{array}$ & 26.95 & 5.22 & 27.78 & 4.93 & 1.19 & 145 & 28.98 & 3.99 & 30.27 & 4.70 & $.01^{*}$ & 187 \\
\hline $\begin{array}{l}\text { Attitude toward } \\
\text { assimilation }\end{array}$ & 9.19 & 2.26 & 8.67 & 2.02 & 1.50 & 153 & 5.37 & 1.99 & 5.43 & 1.94 & .07 & 184 \\
\hline $\begin{array}{l}\text { Contact with } \\
\text { outgroup }\end{array}$ & 2.58 & .96 & 2.81 & .94 & .90 & 159 & 2.52 & 1.09 & 2.58 & 1.05 & .44 & 186 \\
\hline
\end{tabular}

Table 3. Results of t-test and descriptive statistics for contact with outgroup by ethnicity

\begin{tabular}{|l|l|l|l|l|l|l|}
\hline ethnicity & Macedonian & \multicolumn{4}{|l|}{ Albanian } & \\
\hline & M & SD & M & SD & $t$ & df \\
\hline
\end{tabular}




\begin{tabular}{|l|l|l|l|l|l|l|}
\hline greeting & 3.54 & 1.22 & 3.15 & 1.27 & $.88^{\star}$ & 215 \\
\hline texting & 2.25 & 1.23 & 2.23 & 1.35 & 1.30 & 216 \\
\hline participating in physical activities & 2.72 & 1.24 & 2.33 & 1.26 & $.20^{\star}$ & 214 \\
\hline spending free time & 1.89 & 1.04 & 1.87 & 1.23 & 2.12 & 214 \\
\hline home visiting & 1.52 & .93 & 1.61 & 1.03 & 1.81 & 213 \\
\hline
\end{tabular}

\section{Prediction}

Multi regression analysis is used to predict the attitudes towards outgroup. Regarding the majority group, the attitudes towards assimilation are predicted by the direct contact, contact frequency (greeting, texting, participating in joint physical activities, spending free time together and home visits) and ethnic identity. In table 4 and table 5 the correlation between variables in majority and minority groups is presented.

The data point out that ethnic identity, as well as contact frequency (home visits to outgroup members), represent a significant quantity of attitudes toward assimilation $\left(R=0.34 ; R^{2}=0.24 ; F(8.51)=3.32, p<0.05\right)$. The model explains $24 \%$ of the criterion variance. Ethnic identity mostly contributes in explaining attitudes towards assimilation. From the outgroup member contact, only home visits to outgroup members, appear as a predictor of the attitudes towards assimilation for the majority group. Other types of contact frequency like greeting, texting, participating in joint physical activities and free time spent with outgroup member, do not appear as predictors of attitude towards assimilation in this model.

Table 4. Coefficient correlation between variables in the majority group

\begin{tabular}{|c|c|c|c|c|c|c|c|c|c|}
\hline \multirow{2}{*}{ 1. multiculturalism } & 1 & 2 & 3 & 4 & 5 & 6 & 7 & 8 & 9 \\
\hline & & & & & & & & & \\
\hline 2. assimilation & .096 & & & & & & & & \\
\hline 3. direct contact & .840 & $-.256^{*}$ & & & & & & & \\
\hline $\begin{array}{l}\text { 4. number of acquaintances from } \\
\text { outgroup }\end{array}$ & .156 & -.068 & $.237^{*}$ & & & & & & \\
\hline 5. greeting & .173 & $-.207^{\star}$ & $.291^{* *}$ & $.241^{*}$ & & & & & \\
\hline 6. texting with & -.016 & -.078 & $.203^{*}$ & .064 & $.277^{* *}$ & & & & \\
\hline $\begin{array}{l}\text { 7. participate in joint physical } \\
\text { activities }\end{array}$ & .120 & -.040 & $.255^{* *}$ & .031 & $.415^{\star \star}$ & $.357^{\star \star}$ & & & \\
\hline 8. spend free time & .101 & $-.296^{\star \star}$ & $.278^{* \star}$ & .111 & $.379^{\star \star}$ & $.588^{\star \star}$ & $.401^{* *}$ & & \\
\hline 9. home visiting & .038 & $-.317^{\star \star}$ & .179 & -.011 & $.356^{\star \star}$ & $.459^{* \star}$ & $.321^{* *}$ & $.738^{* *}$ & \\
\hline 10. identity (NAIT) & .126 & .168 & $\begin{array}{l}.028 \\
\end{array}$ & $-.286^{*}$ & .182 & -.015 & -.018 & -.027 & -.033 \\
\hline
\end{tabular}

Table 5. Coefficient correlation between variables in the minority group

\begin{tabular}{|c|c|c|c|c|c|c|c|c|c|}
\hline & 1 & 2 & 3 & 4 & 5 & 6 & 7 & 8 & 9 \\
\hline \multicolumn{10}{|l|}{ 1. multiculturalism } \\
\hline 2. assimilation & $.189^{* *}$ & & & & & & & & \\
\hline 3. direct contact & .095 & .082 & & & & & & & \\
\hline $\begin{array}{l}\text { 4. number of acquaintances from } \\
\text { outgroup }\end{array}$ & .004 & .010 & -.008 & & & & & & \\
\hline 5. greeting & -.007 & -.031 & $.195^{*}$ & $.297^{*}$ & & & & & \\
\hline 6. texting with & -.031 & .101 & $.322^{\star \star}$ & .062 & $.474^{\star \star}$ & & & & \\
\hline $\begin{array}{l}\text { 7. participate in joint physical } \\
\text { activities }\end{array}$ & $-265^{* *}$ & .007 & $.417^{* \star}$ & $.308^{* *}$ & $.489^{* \star}$ & $.416^{* *}$ & & & \\
\hline 8. spend free time & $-199^{*}$ & .091 & $.483^{\star \star}$ & $.284^{*}$ & $.464^{* *}$ & $.589^{* *}$ & $.716^{\star *}$ & & \\
\hline 9. home visiting & $-.227^{*}$ & .084 & $.429^{* *}$ & $.311^{* *}$ & $.420^{* *}$ & $.578^{* \star}$ & $.608^{* *}$ & $.739^{* \star}$ & \\
\hline 10. identity (NAIT) & $.337^{\star *}$ & -009 & $-.196^{*}$ & .062 & -.021 & -.077 & -.106 & $-.219^{*}$ & $-.264^{* *}$ \\
\hline
\end{tabular}




\section{Discussion}

The goal of this study is to analyze the differences of attitudes toward multiculturalism and assimilation in majority groups (Macedonians) and minority (Albanians) as well as to which extent the intergroup attitudes can be predicted, based on ethnic identity and outgroup contact. The data show that there is statistically significant difference on intergroup attitudes between the members of majority group, Macedonians, and members of minority group, Albanians. More specifically, young Albanians (minority) expressed that they favor more multiculturalism compared to young Macedonians (majority). Young people of both groups differ in expressing their attitude towards assimilation. Unlike young Albanians, young Macedonians express that they favor more assimilation. The results are in compliance with findings of other research studies (Verkuyten \& Martinovic, 2006; Verkuyten, 2005; Ajduković \& Čorkalo, 2008). Members of minority groups perceive multiculturalism as an opportunity to maintain their identity. In this regard, they stress that they favor more multiculturalism, while the majority perceives the same as a risk to their identity and therefore it results as less favored. Members of majority favor more attitudes towards assimilation. In the other hand, for the minority group assimilation implies merging or waiving their culture and identity which makes them express reserve or not favor assimilation. This study found no differences in contact with the outgroup among the Albanian and Macedonian youth. This data is not within the framework of other research that show that minority group members express they have more contact with outgroup members (Verkuyten, 2009). However, it can also be explained in social context of the participants (Osmani Ballazhi et al., 2016). The subjects included in this research learn in mono-ethnic schools that do not offer "meeting" opportunities with outgroup members which would contribute to contacts regardless of ethnicity. Nevertheless, the data show differences regarding the contact frequency. Unlike young Albanians, Macedonians express that they greet more often as well as that they participate more often in physical activities with Albanians. The data also show that the ethnic identity intensity as well as home visits with outgroup members are two factors that explain the attitudes of young Macedonians towards assimilation. The prediction of attitudes towards assimilation in majority group, from the ethnic identity and contact - home visits, is within the frames of the contact theory, which highlights that the quality of friendship with outgroup members has effects on prejudice towards outgroup. Other research conducted in Macedonia also show results that the quality of the outgroup member contact contributes to intergroup relations (Osmani Ballazhi et al., 2014). In other words, it is important to create outgroup contact opportunities between citizens, especially youngsters in the Republic of Macedonia which will result in friendships among different ethnic group members. These friendships will further lead to reduction, respectively decrease of favoring assimilation and contribute to the development of a multiethnic society.

\section{Literature}

[1] Ajdukovic, D. \& Biruski Čorkalo, D. (2008). Caught between the ethnic sides: Children growing up in a divided post-war community. International Journal of Behavioral Development, 32 (4), 337-347.

[2] Allport, G. W. (1949). The Nature of. American Quarterly, 1, 58-82.

[3] Berry, W. J. (2011). Integration and Multiculturalism: Ways towards Social Solidarity. Papers on Social Representations 20 2.1-2.21

[4] Biruški, D. Č., \& Ajdukovič, D. (2012). Sto odreðuje meðuetnicke stavove adolescenata u podijeljenoj zajednici?. Drustvena Istrazivanja, 21(4), 901-921.

[5] Brown, A.R., Eller, A., Leeds, S. \& Stace, K. (2007). Intergroup contact and intergroup attitudes: A longitudinal study. European Journal of Social Psychology, 37, 692-703.

[6] Čorkalo, D. \& Kamenov, Ž. (2003). National identity and social distance: Does in-group loyalty lead to outgroup hostility? Review of Psychology, 10 (2) 85-94

[7] Osmani Ballazhi, Sh., Ahmeti, K., Asani, L., Neziri, I., Bajrami, F. (2014). Education on multiculturalism and intergroup attitudes. In M. Stojanovski, et al. (Eds.), Practicum of future pedagogues, teachers and kindergarten teachers in multicultural environments -experiences and challenges. Paper presented at Firts International Conference, Faculty of Philosophy Ss. Cyril and Methodius University, Skopje, 27-29 November (pp. 325-331).

[8] Osmani Ballazhi, Sh., Neziri, I., Ahmeti, K., Bajrami, F. (2016). Albanian and Macedonian Pedagogy Students' Positive Intergroup Attitudes and Contacts with the Out-Group. In V. Arnaudova (Eds.), Proceeding of papers from International conference on theory and practice in psychology. Paper presented at International conference 
on theory and practice in psychology, Faculty of Philosophy -Skopje, 30 October-1 November 2014 (pp.755770). Skopje: Faculty of Philosophy.

[9] Pettigrew, F. Th. \& Tropp, L.R. (2011). When groups meet: The dynamics of Intergroup Contact. New York: Psychology Press.

[10] Schlueter, E. \& Scheepers, P. (2010). The relationship between outgroup size and anti-outgroup attitudes: A theoretical synthesis and empirical test of group threat and intergroup contact theory. Social Science Research, $39,285-295$.

[11] Verkuyten, M. (2004). Everyday ways of thinking about multiculturalism. Ethnicities, 4, (1), 53-74.

[12] Verkuyten, M. (2005). Ethnic Group Identification and Group Evaluation Among Minority and Majority Groups: Testing the Multiculturalism Hypothesis. Journal of Personality and Social Psychology, 88(1), 121-138

[13] Verkuyten, M. \& Martinovic B. (2006). Understanding multicultural attitudes: The role of group status, identification, friendships, and justifying ideologies. International Journal of Intercultural Relations, 30, 1-18.

[14] Verkuyten, M. (2009). Support for Multiculturalism and Minority Rights: The role of National Identification and Out-Group Threat. Social Justice Research, 22, 31-52. 